\title{
A COMPARATIVE CLINICAL OUTCOME STUDY OF DESCEMET MEMBRANE ENDOTHELIAL KERATOPLASTY (DMEK) AND TRADITIONAL DESCEMET STRIPPING ENDOTHELIAL KERATOPLASTY (DSEK) IN INTERVENTIONAL PROSPECTIVE OUTCOMES
}

\author{
Dharamveer Singh Choudhary¹, Anamika Chaudhary22, Nikhil Aggarwal3, Mahendra Kumar Jharwal', Bhavit Roat ${ }^{5}$
}

${ }^{1}$ Assistant Professor, Department of Ophthalmology, SMS Medical College, Jaipur, Rajasthan, India.

${ }_{2}^{2}$ MBBS, Rajasthan University of Health Sciences, Jaipur, Rajasthan, India.

${ }^{3}$ Professor and HOD, Department of Ophthalmology, SMS Medical College, Jaipur, Rajasthan, India.

${ }_{4}^{4}$ Senior Resident, Department of Ophthalmology, SMS Medical College, Jaipur, Rajasthan, India.

5MBBS, SMS Medical College, Jaipur, Rajasthan, India.

\section{BACKGROUND}

\section{ABSTRACT}

Patients presenting to the eye clinics with endothelial decomposition who underwent endothelial keratoplasty were included in the study. Data including patient demographics, visual acuity, endothelial cell counts, and complications were recorded at baseline as well as 3 and 6 months and 1 year post-operatively.

The primary outcome for this study was BCVA at 6 months and 1 year. Secondary outcomes included endothelial cell counts and complication rates.

\section{MATERIALS AND METHODS}

A total of 100 consecutive eye patients which met inclusion criteria underwent endothelial keratoplasty and were included in this study.

\section{RESULTS}

Of these 50 patients' eyes had DSEK, while other 50 patients' eyes had DMEK. After controlling for baseline visual acuity study, participants undergoing DMEK had better improvement in visual acuity compared with DSEK in early postoperative period, but not at 6 months $(p=0.310)$ and 1-year $(p=0.105)$ follow-up. DMEK patients experienced an average of $34.75 \%$ endothelial cell loss compared with $33.5 \%$ in DSEK at the end of 1-year. There were 2 primary graft failures after DMEK compared with 0 after DSEK, but this was not a statistically significant difference $(p=0.0475)$.

\section{CONCLUSION}

In early post-operative period, DMEK offers a visual improvement in the early post-operative period but had more endothelial cell loss. However, at the end of 1-year follow-up, difference between the two procedures gradually narrowed down in terms of BCVA and ECL (Endothelial Cell Loss).

\section{KEY WORDS}

Descemet Membrane Endothelial Keratoplasty (DMEK), Additional Descemet Stripping Endothelial Keratoplasty (DSEK), Clinical Outcome.

HOW TO CITE THIS ARTICLE: Choudhary DS, Chaudhary A, Aggarwal N, et al. A comparative clinical outcome study of Descemet membrane endothelial keratoplasty (DMEK) and traditional Descemet stripping endothelial keratoplasty (DSEK) in interventional prospective outcomes. J. Evolution Med. Dent. Sci. 2018;7(49):5225-5228, DOI: 10.14260/jemds/2018/1159

\section{BACKGROUND}

Penetrating Keratoplasty (PK) had been considered the gold standard for treating corneal endothelial dysfunction but delayed rehabilitation, prolonged visual recovery, high rejection rate, suture related complications etc. made it less popular. In 1998, Melles and co-worker(1) first described a new technique of component keratoplasty and called it 'posterior lamellar keratoplasty' or PLK. Francis W Price(2) further modified and simplified the technique in preparation of the recipient's bed by stripping off the recipient Descemet membrane, now popularly called 'Descemet stripping endothelial keratoplasty' or DSEK.

'Financial or Other Competing Interest': None.

Submission 17-10-2018, Peer Review 20-11-2018,

Acceptance 26-11-2018, Published 03-12-2018.

Corresponding Author:

Dr. Anamika Chaudhary,

8/214, Kumbha Marg, Pratap Nagar,

Jaipur-302033, Rajasthan, India.

E-mail: anamika.ds.jaipur@gmail.com

DOI: $10.14260 /$ jemds $/ 2018 / 1159$

\section{(c) $(1)(5)$}

Recent studies suggest that near anatomic replacement of endothelial tissue (DMEK) produces improved visual acuity results compared to Descemet Stripping Endothelial Keratoplasty (DSEK).(3) However, according to the Eye Bank Association of America, DMEK still accounted for less than $15 \%$ of endothelial keratoplasties in the United States in 2015 as compared to DSEK, which accounts for $50 \%$ of total endothelial transplants. This suggests that the majority of endothelial keratoplasty (EK) surgeons have not yet adopted DMEK or is early on the DMEK learning curve. The goal of this study is to provide both cornea specialists and patients with information on clinical outcomes of DSEK vs DMEK. In this study, we had prospectively evaluated 1-year clinical outcomes of the first 50 consecutive DMEKs performed at one centre versus 50 consecutive DSEK surgeries performed during the same time period on patients with endothelial decompensation due to pseudophakic, aphakic bullous keratopathy and Fuchs' endothelial dystrophy. 


\section{MATERIALS AND METHODS}

In this non-randomised, consecutive and interventional prospective case studies, the first 100 consecutive patients (Age $\geq 18$ years with BCVA $\leq 20 / 400$ ) with endothelial dysfunction who were enlisted for corneal grafting in our central register were included for DSEK and DMEK. Patients with dense central corneal stromal scarring, irregular and deformed anterior chamber (AC), gross peripheral anterior synechia (PAS), uncontrolled glaucoma and gross posterior segment pathology detected by B-scan were excluded from the study.

The prerequisites donor included in the study were young and healthy, preferably below 60 years of age and had endothelial count $>2200$ cells/sqmm as determined by specular microscope with scleral rim of $2 \mathrm{~mm}$ all around. All 100 surgeries were performed by a single surgeon from January 2016 to June 2018. The surgery was performed under conventional peribulbar anaesthesia. Pupillary dilation was required only in cases where it was combined with cataract extraction with posterior chamber intraocular lens (PCIOL) implantation or scleral fixated IOL. In the study, we included actual 3 and 6-month and 1-year visual acuity results even if they had primary graft failure requiring repeat endothelial keratoplasty. Pre-specified secondary outcomes included endothelial cell count at 6 months and 1 year as well as complications such as re-bubble rate, primary graft failure and graft rejection.

The study was approved by the Institutional Review Board of SMS Medical College, Jaipur, India and adhered to the Declaration of Helsinki.

All DSEK surgeries used standardised needle insertion technique. An 8.0 - $8.5 \mathrm{~mm}$ area of host Descemet membrane was stripped under air using a reverse Sinskey hook and pealed with a Descemet stripper. Donor tissue was prepared by using 8.0 - $8.5 \mathrm{~mm}$ Barron-Hessburg punch (Katena Products, Denville, NJ). The endothelial disc was gently separated from the remaining donor cornea. It was then nudged with a modified cystotome needle and inserted through a scleral based $5 \mathrm{~mm}$ scleral tunnel. The incision was then closed with 10.0 nylon suture and air was injected to achieve a partial air fill. Gentle fluid waves and stroking motions on the surface of the cornea were used to unfold and center the graft. A full air fill was performed for a period of 8 10 minutes and then the air bubble was reduced to $80 \%$ volume and the anterior chamber to physiologic pressure. One drop of $1 \%$ Atropine was used to dilate the pupil. The patient was asked to position horizontally laying face-up for approximately 24 hours post-operatively.

For DMEK surgeries, recipient preparation and stripping of Descemet membrane was performed as described previously for DSEK. Donor corneal tissue was stained with Vision Blue (DORC, Zuidland, Netherlands) to identify the edge of Descemet membrane. The cornea was trephined to 7.75 - $8.25 \mathrm{~mm}$ using a Barron punch and the central Descemet disc was separated from stroma under saline (SCUBA technique) (6) by gently lifting the graft from Descemet side and then grasping in one peripheral point to complete the peel. The scrolled central disc was stained in Vision blue ( $90 \%$ and $10 \%$ Optisol GS) for 5.0 minute and then the dye was rinsed with balanced salt solution. The graft was gently aspirated into a modified Jones Tube in the standardised technique as described previously.(4) The clear corneal wound was extended to 3.2 - $3.5 \mathrm{~mm}$ for the Jones tube and the grafts were injected into the anterior chamber. The incision was closed with 10.0 nylon suture and the chamber was shallowed. Fluid waves were used to orient the graft and gentle peripheral corneal taps were used to unfurl the graft and centralise it under the host. A full air fill was performed for 10 minutes and then the air bubble was reduced to $80 \%$ volume and the anterior chamber to physiologic pressure. One drop of $1 \%$ Atropine was used to dilate the pupil. The patient was asked to maintain supine position for approximately 24 hours post-operatively.

\section{Statistical Analysis}

The independent ' $t$ ' test was performed to analyse differences in baseline characteristics between groups and chi-square for making difference of consequences in between DSEK and DMEK. Chi-square test was performed to analyse differences in complication rates such as re-bubble and graft failure. Statistical significance was defined by an alpha of $<0.05$. All analyses were conducted using EpiCalc version 2000.

\section{RESULTS \\ Demographics}

Mean age of study participants were $68.1 \pm 11.0$ years and $70.6 \pm 9.6$ years for the DSEK and DMEK groups, respectively $(\mathrm{p}=0.198)$, while the mean age of donors were $56.5 \pm 10.5$ years and $62.5 \pm 6.5$ years for the DSEK and DMEK groups, respectively $(p=0.001)$. Transplantation with concurrent cataract surgery (triple procedure) was performed in eye of 15 patients $(30 \%)$ in the DSEK group and 20 eye patients $(40 \%)$ in the DMEK group $(p=0.401)$. The remaining eye patients were of pseudophakic at the time of their initial evaluation (Table 1). No patients were left aphakic in the initial 100 cases for either technique. In both the DSEK and DMEK groups, all cataract surgeries if needed were performed at the same time as the corneal surgery. Patients were followed up for a period of 1 year.

\section{BCVA}

Mean BCVA improved from 0.71 +/- 0.19 logMAR and 0.75+/$0.11 \operatorname{logMAR}$ before surgery to $0.450+/-0.21 \operatorname{logMAR}$ and $0.41+/-0.18$ logMAR at 6 months after DSEK and DMEK, respectively (Table 2; Fig. 1). There was no significant difference in both pre-operative and post-operative visual acuity between DSEK and DMEK eyes $(\mathrm{p}<0.310)$ at 6 months follow-up. Similarly, no significant difference was found postoperatively in both the groups at the end of 1 year (Figure 1).

\section{Endothelial Cell Density}

Mean ECD of donor patient corneas in DSEK eyes decreased from $2645.7 \pm 250.1$ cells $/ \mathrm{mm}^{2}$ before surgery to $2012.1 \pm 274.5$ cells $/ \mathrm{mm}^{2}$ and $1760 \pm 262$ cells $/ \mathrm{mm}^{2}$ at 6 months and 12 months after surgery respectively. Mean ECL was $23.9 \pm 14.0 \%$ and $33.45 \pm 15 \%$ at 6 months and 12 months follow-up respectively. Mean ECD of donor corneas in DMEK eyes decreased from $2521.3 \pm 296.8$ cells $/ \mathrm{mm}^{2}$ before surgery to $1890 \pm 452.2$ cells $/ \mathrm{mm}^{2}$ and $1660 \pm 282$ cells $/ \mathrm{mm}^{2}$ at 6 months and 1-year respectively after surgery. Mean ECL was $25.03 \pm 16.0 \%$ and $34.75 \% \pm 12 \%$. There was no statistically significant difference in pre-operative ECD $(p=0.106)$, nor was there a statistically significant difference in ECL 6 months and 1 year after surgery $(p=0.579)$ between DSEK and DMEK. 


\section{Postoperative Complications}

Air Injections (Re-bubbling) was performed in 4 eyes with total detachment after DSEK and 8 eyes with partial detachment after DMEK $(\mathrm{p}=0.28)$. All detachments resolved after 1 air injection. There were no immunologic graft rejections for the 6 months in the DMEK group. One eye in the DSEK group had an immunologic rejection episode in this period that resolved completely with topical steroid therapy ( $p>0.99)$.

Iatrogenic Primary Graft Failure Status: - There were no cases of Iatrogenic Primary Graft Failure (IPGF) in the DSEK group. Four eyes had IPGF after DMEK $(p=0.12)$. Three of the IPGF DMEK cases were the result of placement of an upsidedown graft and 1 was the result of a break in surgical technique.

\begin{tabular}{|c|c|c|c|}
\hline $\begin{array}{l}\text { Demographic } \\
\text { Variables }\end{array}$ & $\begin{array}{c}\text { DSEK } \\
(\mathrm{N}=50)\end{array}$ & $\begin{array}{l}\text { DMEK } \\
(\mathrm{N}=50)\end{array}$ & $\begin{array}{c}\mathbf{P} \\
\text { value }\end{array}$ \\
\hline Mean Age of Host $( \pm$ SD) & $65.3 \pm 12.0$ & $68.1 \pm 9.5$ & 0.198 \\
\hline Donor Mean Age $( \pm S D)$ & $56.1 \pm 7.0$ & $62.1 \pm 6.0$ & $0.001^{*}$ \\
\hline $\begin{array}{l}\text { Triple Procedure } \\
\text { (No and \%) }\end{array}$ & $15(30 \%)$ & $20(40 \%)$ & 0.401 \\
\hline $\begin{aligned} \text { BCVA (Lc } \\
\text { (Pre-opera }\end{aligned}$ & & 0.11 & \\
\hline $\begin{array}{l}\text { BCVA (Log) (6 Months); } \\
\text { Mean }( \pm \text { SD) }\end{array}$ & $\begin{array}{c}0.45 \pm \\
0.21\end{array}$ & & 0.310 \\
\hline $\begin{array}{r}\mathrm{BCVA}( \\
\mathrm{Me}\end{array}$ & $\begin{array}{c}0.31 \pm \\
0.21 \\
\end{array}$ & $\begin{array}{l}0.21 \pm \\
0.15 \\
\end{array}$ & 0.107 \\
\hline $\begin{array}{l}\text { Donor Endothelial Cell } \\
\text { Count: Cell } / \mathrm{mm}^{2} \\
\text { (Pre-Op) No } \pm \mathrm{SD} \\
\end{array}$ & $\begin{array}{c}2645 \pm \\
254\end{array}$ & $\begin{array}{c}2521 \pm \\
296\end{array}$ & $0.027^{*}$ \\
\hline ECD (6 Months) No \pm SD & $2012 \pm 274.5$ & $2521 \pm 452.2$ & 106 \\
\hline $\begin{array}{c}\text { ECL (Endothelial Cell } \\
\text { Loss) [6 Months] No } \pm \text { SD }\end{array}$ & $\begin{array}{l}23.3 \% \pm \\
14 \% \\
\end{array}$ & $\begin{array}{c}25.02 \% \pm \\
16 \% \\
\end{array}$ & 0.568 \\
\hline $\begin{array}{c}\text { ECL (Endothelial Cell } \\
\text { Loss) [6 Months] No } \pm \text { SD) }\end{array}$ & $\begin{array}{c}33.3 \% \pm \\
14 \% \\
\end{array}$ & $\begin{array}{c}34.75 \% \pm \\
12 \% \\
\end{array}$ & 0.579 \\
\hline \multicolumn{4}{|c|}{ *Significant Statistically } \\
\hline \multicolumn{4}{|c|}{$\begin{array}{c}\text { Table 1. Patient's Characteristics according to } \\
\text { DSEK and DMEK }\end{array}$} \\
\hline
\end{tabular}

\begin{tabular}{|c|c|c|c|}
\hline Complication & $\begin{array}{c}\text { DSEK (N=50) } \\
\text { No (\%) }\end{array}$ & $\begin{array}{c}\text { DMEK (N=50) } \\
\text { No (\%) }\end{array}$ & $\begin{array}{c}\text { P } \\
\text { value }\end{array}$ \\
\hline Re-bubbling & $4(8.0)$ & $8(16.0)$ & 0.355 \\
\hline $\begin{array}{c}\text { Immunological } \\
\text { Reaction }\end{array}$ & $2(4.0)$ & $0(0)$ & 0.474 \\
\hline $\begin{array}{c}\text { Iatrogenic Graft } \\
\text { Failure }\end{array}$ & $0(0)$ & $2(4.0)$ & 0.475 \\
\hline Secondary Glaucoma & $1(2.0)$ & $1(2.0)$ & 0.474 \\
\hline Table 2. Complication Rate comparison in DSEK and DMEK \\
\hline
\end{tabular}

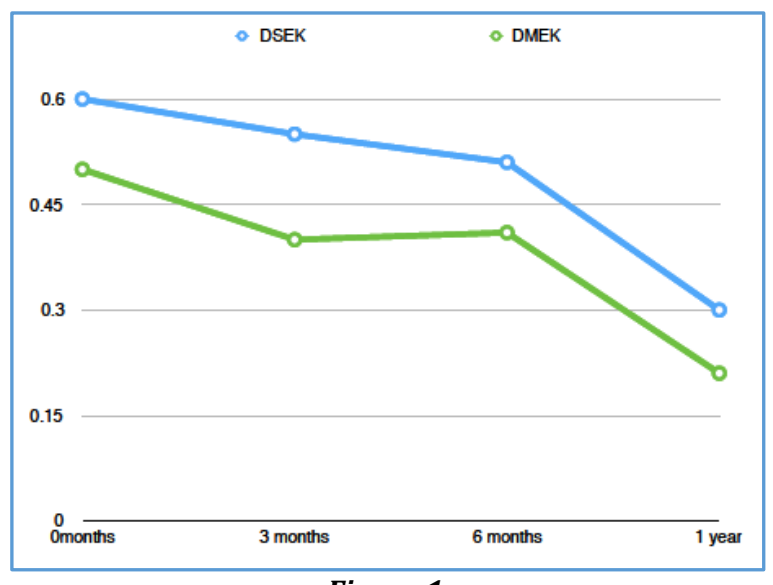

Figure 1

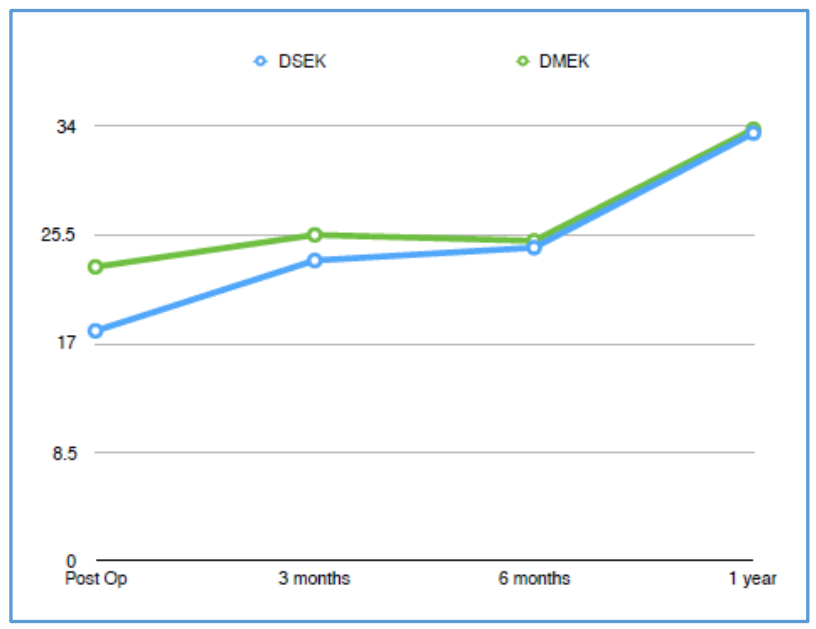

Figure 2

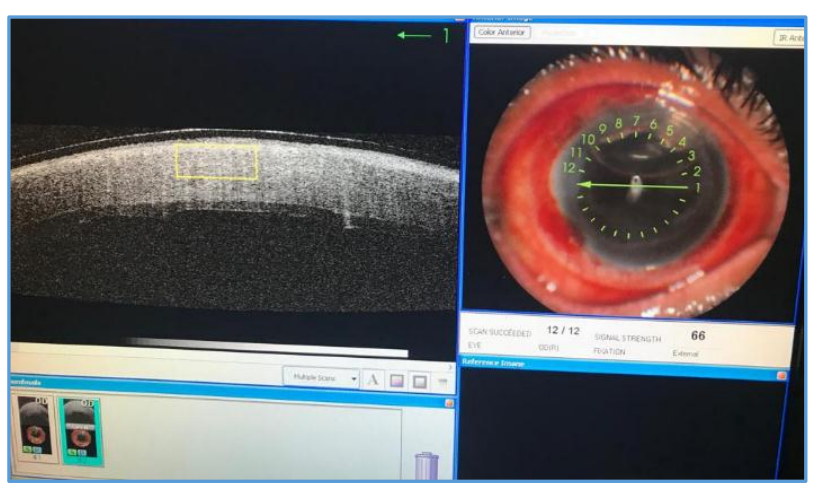

Figure 3

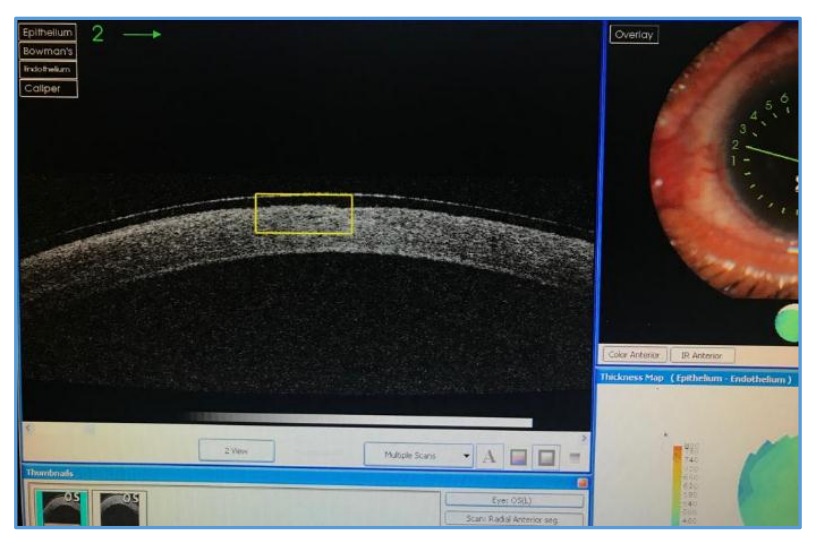

Figure 4

\section{DISCUSSION}

Modern endothelial keratoplasty use has increased rapidly since its inception 15 years ago. It has become the preferred procedure for surgical treatment of endothelial dysfunction and its acceptance by surgeons has increased, as standardised surgical techniques were developed that preserved the endothelium and delivered excellent results for patients. Compared with DSAEK, DMEK has several accepted advantages. Descemet membrane endothelial keratoplasty offers rapid visual rehabilitation, minimal astigmatic and hyperopic shift, lower higher-order aberrations and a lower rejection rate.(5)

This study compared the results of our 50 standardised DSEK surgeries with our 50 standardised DMEK surgeries. We have found better visual recovery with standardised DMEK compared with standardised DSEK in the early post- 
operative period. However, difference in the visual acuity gradually tapered down and at the end of 6 months and 1year follow-up, there was no significant statistical difference found between the two groups in terms of visual acuity.

The 6-month post-operative visual results in our DMEK eyes were comparable with the post-operative 6-month results published previously.(6) Six months after DSEK, BCVA was $20 / 40$ or better in $80 \%$ to $97 \%$, Li et al(6) also reported $20 / 25$ visual acuity in $36.1 \%$ of patients 6 months after surgery and found that the vision continued to improve over time. Our visual outcomes for DSEK patients in this study were similar to these previously published results. $(5,6)$ Finally, in our DSEK patients, the percentage of eyes achieving 20/20 BCVA in our DSEK series here (13\%) as compared to DMEK series percentage (24\%). In this study, we found no statistically significant difference in ECL at 6 months between the DMEK and DSEK groups, which was $28 \%$ and $26 \%$, respectively. However, cell loss in early post-operative period was more in DMEK as compared to DSEK. We believe that surgical experience and standardised technique to perform DMEK may help in reducing cell loss during intraoperative period. Our cell loss was very similar to that of previous publications, which report losses in the range of $16 \%$ to $50 \%$ after DSEK and 20\% to 32\% after DMEK 6 months after surgery. $(7,8)$

In DSEK grafts, air reinjection is required only if the graft is totally detached and free floating in the anterior chamber. Partial DSAEK detachments can be observed and usually will attach spontaneously. With DMEK grafts, air injections are performed for partial detachments. In our study, 2 cases (4\%) in the DSEK group and 6 cases (12\%) in DMEK group.

There was no significant difference in re-bubbling rates between groups $(p=0.28)$. Tourtas et al(9) reported rebubbling in $82 \%$ of patients after DMEK and $20 \%$ after DSAEK. Guerra et al(10) reported that $33 \%$ of the DMEK eyes required a re-bubbling procedure compared with $7 \%$ of the DSAEK eyes. Dapena et al(7) showed a marked decline in the re-bubbling rate from $20 \%$ to $4.4 \%$ and attributed the improvement to the effect of the learning curve.

\section{CONCLUSION}

There may be faster visual recovery after DMEK surgery compared with DSEK; however, endothelial cell loss is worse and there are higher rates of complications such as primary graft failure in learning curve. Given the recent EBAA statistics on tissue utilisation for DMEK,(11) it seems likely that many surgeons either have not yet begun to perform the procedure or are on the early learning curve. We postulate that placing less stress on the endothelium at every step is important in preventing endothelial cell damage.(12,13) But once the learning curve threshold is reached, complication rates are minimal and results are excellent in terms of visual acuity, endothelial cell loss and rehabilitation.

\section{REFERENCES}

[1] Melles GR, Eggink FA, Lander F, et al. A surgical technique for posterior lamellar keratoplasty. Cornea 1998;17(6):618-26.

[2] Price MO, Price FW Jr. Endothelial keratoplasty - a review. Clin Exp Ophthalmol 2010;38(2):128-40.

[3] Hamzaoglu EC, Straiko MD, Mayko ZM, et al. The first 100 eyes of standardized descemet stripping automated endothelial keratoplasty versus standardized descemet membrane endothelial keratoplasty at one institution. Ophthalmology 2015;122(11):2193-9.

[4] Eye Banking Statistical Report. America EBAo, 2014.

[5] Price MO, Giebel AW, Fairchild KM, et al. Descemet's membrane endothelial keratoplasty: prospective multicenter study of visual and refractive outcomes and endothelial survival. Ophthalmology 2009;116(12):2361-8.

[6] Li JY, Terry MA, Goshe J, et al. Three-year visual acuity outcomes after Descemet's stripping automated endothelial keratoplasty. Ophthalmology 2012;119(6):1126-9.

[7] Ham L, Dapena I, Liarakos VS, et al. Midterm results of Descemet membrane endothelial keratoplasty: 4 to 7 years clinical outcome. Am J Ophthalmol 2016;171:113-21.

[8] Rodríguez-Calvo-de-Mora M, Quilendrino R, Ham L, et al. Clinical outcome of 500 consecutive cases undergoing Descemet's membrane endothelial keratoplasty. Ophthalmology 2015;122(3):464-70.

[9] Tourtas T, Laaser K, Bachmann BO, et al. Descemet membrane endothelial keratoplasty versus Descemet stripping automated endothelial keratoplasty. Am J Ophthalmol 2012;152(6):1082-90.e2.

[10] Guerra FP, Anshu A, Price MO, et al. Descemet's membrane endothelial keratoplasty: prospective study of 1-year visual outcomes, graft survival and endothelial cell loss. Ophthalmology 2011;118(12):2368-73.

[11] Jardine GJ, Holiman JD, Stoeger CG, et al. Imaging and quantification of endothelial cell loss in eye bank prepared DMEK grafts using trainable segmentation software. Curr Eye Res 2014;39(9):894-901.

[12] Writing Committee for the Cornea Donor Study Research Group, Sugar A, Gal RL, et al. Factors associated with corneal graft survival in the cornea donor study. JAMA Ophthalmol 2015;133(3):246-54.

[13] Writing Committee for the Cornea Donor Study Research Group, Lass JH, Benetz BA, et al. Donor age and factors related to endothelial cell loss 10 years after penetrating keratoplasty: Specular Microscopy Ancillary Study. Ophthalmology 2013;120(12):242835. 